folk/ed. Derg, 2021; 27(4)-108. sayı

DOI: $10.22559 /$ folklor.1953

\title{
Animasyon (Çizgi Film) Tarihine Kültür Aktarımı Açısından Bir Bakış*
}

\section{A Look at the History of Animation (Cartoon) in Terms of Cultural Transfer}

\section{Erkan Aslan ${ }^{* *}$}

Öz

Gelişen teknolojiye koşut olarak birçok disiplinin çalışma alanında köklü değişiklikler meydana gelmektedir. Özellikle folklor gibi bilim dalları, veri toplama ve inceleme açısından, dijital alanlardan gün geçtikçe daha fazla yararlanmaktadır. $\mathrm{Bu}$ bağlamda, teknolojik gelişmelere bağlı olarak ortaya çıkan animasyon gibi türler, içerisinde barındırdığı kültürel ögeler nedeniyle, 21. yüzyılda çağdaş bir "folklor anlatısı" olarak işlev görmektedir. Yaklaşık 100 yıllık bir tarihe sahip olan animasyonun, özellikle Disney Stüdyosu'nun kurulmasıyla folklorik bir alt yapıya sahip olduğu söylenebilir. Bu açıdan bakıldığında animasyonun, kültür aktarımı konusunda da önemli bir işleve sahip olduğu görülmektedir. Bu durumun belirgin

Geliş tarihi (Received): 13-04-2021 - Kabul tarihi (Accepted): 2-09-2021

* Bu makale, kaynaklar kısmında künyesi verilen yüksek lisans tezi esas alınarak oluşturulmuştur. Bk. (Aslan, 2015)

** Dr., Gazi Üniversitesi Sosyal Bilimler Enstitüsü Türk Halk Bilimi Anabilim Dalı Doktora Programı Mezunu. Gaei University Social Sciences Institute, Department of Turkish Folklore, Ph.D. Programme.

aslan36@hotmail.com. ORCID 0000-0002-5519-8486 
bir örneğini Japonya oluşturmaktadır. Batı'dan aldığı tekniklere kendi kültürel unsurlarını katarak oluşturduğu animeler, Japon kültürünün popülerleşmesinde önemli bir aracıdır. Türkiye' de ise yaklaşık 60 yıllık bir tarihe sahip olan animasyon, özellikle TRT Çocuk kanalının kurulması ile büyük bir gelişme göstermiş ve Türk kültürünün bu alanda temsili sağlanmıştır. Son yıllarda animasyona aktarılan Dede Korkut Hikâyeleri ve Keloğlan gibi anlatılar, animasyon ile folklor ilişkisini yansıtan belirgin örneklerdir. Bununla birlikte üniversitelerde açılan animasyon bölümleri, profesyonel animatör yetişmesine olanak tanımıştır. Yine animasyon, yarattığı kültür ekonomisi ile büyük bir sektör durumundadır. Animasyonun bütün bu özellikleri göz önüne alındığında 21. yüzyılın en önemli kültür aktarım kanalından birisi olduğunu söylemek mümkündür. Bu çalışmada animasyon ve kültür aktarımı arasındaki ilişki, animasyon tarihi üzerinden sorgulanmış ve animasyonun kültür aktarımı konusunda oldukça büyük bir etki gücüne sahip olduğu sonucuna varılmıştır.

Anahtar sözcükler: animasyon, animasyon tarihi, çizgi film, folklor, kültür aktarımı

\begin{abstract}
As a result of technological developments, radical changes have taken place in the field of study of many disciplines. In particular, science branches like folklore are using more and more from digital fields in terms of data collection and analysis. In this context, genres such as animation, which arise due to technological developments, function as a contemporary "folklore narrative" in the 21 st century due to the cultural element they contain. The animation, which has a history of about 100 years, has a folkloric infrastructure, especially with the establishment of the Disney Studio. From this point of view, it will be seen that animation also has a great deal of function on culture transfer. A clear example of this is Japan. The animations created by adding their own cultural elements to the techniques they acquire from the West are an important tool in the popularization of Japanese culture. Animation, which has a history of about 60 years in Turkey, has shown a great improvement especially with the establishment of TRT Children's channel and it has been provided with the representation of Turkish culture. Dede Korkut Stories and Keloğlan, which have been transferred to animation in recent years, are examples that reflect the relationship between animation and folklore. Moreover, the animation departments at the universities allow the professional animator to train. When all these features of the animation are taken into consideration, it is possible to say that it is one of the most important cultural transmission channels of the 21 st century. In this study the relationship between animation and culture transfer, was questioned on animation history and it has been concluded that animation has a great influence on cultural transfer.
\end{abstract}

Keywords: animation, animation history, cartoon, folklore, culture transfer 


\section{Extended summary}

Both culture and cultural transfer are a dynamic phenomenon that changes according to time and place. In the last century, it is seen that the transfer of culture has largely passed from verbal sources such as mother, father, grandfather, grandmother to television, computer and technological tools. This change in the topic of cultural transfer leads to a rethinking of the concept of both folk and space among folklorists. Thus, today such genres as animation are now considered as areas where folkloric material can be compiled. From this point of view, it can be said that animation is the most important cultural transmission channel today. In this study, the main goal is to question the importance of animation in terms of cultural transfer through the history of animation. Since the study was focused on Turkey, the review was conducted based on the history of animation outside Turkey and Turkey.

Animation, which has been of great importance in transferring culture from the first periods it appeared to the present day, has increasingly increased its importance with the developing technology. In particular, the transition of animation from two to three dimensions has made fundamental changes in its target audience. Three-dimensional animations have moved the cultural transfer to a wider dimension by calling out to children as well as adults. In addition, this situation is noteworthy in terms of the holistic transfer of culture.

The first examples of animation in the world were shot in accordance with the flash sketch method in the early 1900s. Then the animations were drawn on paper and animated from here. Although these first attempts at animation do not involve a deep folkloric infrastructure, its close relationship to the fairy tale gives hints that it will have folkloric content in the future. As a matter of fact, with the establishment of the Disney Studio, animation has become almost a contemporary tale. Disney Studio produced the first color and sound animations and captured the realistic style and animated the fairy tale Snow White and the Seven Dwarfs. The fact that the tale is very popular today is actually related to this production of Disney Studio. Thus, while a tale gained popularity on a global scale thanks to animation, it also dragged similar examples in local cultures towards extinction.

In the 1940s, many animation companies were established outside the United States, especially in Europe. Of these, it can be seen that the animation called Smurf / Smurfs, made in Belgium, is used a lot in the field of cultural economics. Smurfs that create an image in many areas, from stationery to souvenirs two more animated films were shot in 2011 and 2013 using the real characters. The characters in these animated films were then presented to the consumer in the form of a surprise egg toy. These toys, which have attracted a lot of attention in Turkey, have created a large market and have provided a folkloric image to be seen almost everywhere. This situation shows that animation stands at an important point in terms of both cultural transfer and cultural economy.

It is known that animations are produced in Japan as well as the American and European continents. The animation produced in Japan presents a very interesting example in terms of cultural transfer. Japan has added its own myth and culture to the animation techniques it has received from the West, produced a new style of animation and named it anime. Animes have 
been a great help in conveying Japan's own culture. This shows that in order to popularize a culture, it is not necessary to be in the Western cultural circle. Today, the basis of animations, all of which are made with computers, dates back to the 1980s. Making the animation completely by computer allowed obtaining frames as realistic as a cinema image. Thus, the importance of animation in terms of audience and cultural transfer has increased.

The first attempts of animation in Turkey date back to the 1950s. It is seen that folkloric elements are frequently included in the first period Turkish animations. This is due to the close relationship of animation with culture. Although folkloric elements are frequently included in the first period Turkish animations, it is not said to arouse enough interest. Because in this period, the role of cartoonists in the development of the art of animation is great. The fact that cartoonists do not show enough interest in animation in Turkey has led to a negative result in terms of the development of this genre. In addition, it can also be seen that Turkish animation art developed in the 1980s and received various awards.

In the 1990s, it is seen that many animation departments were opened within the university in Turkey. The fact that animation takes place as a department in universities is very important in training professional animators. Also, TRT Children's Channel, which started broadcasting in 2008, stands at an important point in terms of animation culture relationship. It is seen that cultural images are included in the animations produced in TRT Children's Channel. In this way, both the way of implementing products belonging to Turkish culture has been opened and the animation companies have been allowed to find a ready-made channel that can publish the animations they have made. The animated series called Dede Korkut Stories, which was screened on TRT Children's Channel, clearly demonstrates the importance of animation in cultural transmission. This animated series, which was created on the basis of the Book of Dede Korkut, which has an important place in Turkish narratives, has enabled children to learn many cultural elements. Studies have revealed that this animated series provides a great deal of recognition of the heroes of Dede Korkut Stories by children. This situation again reveals the power and importance of animation in the practical transfer of culture.

It is possible to put the main conclusions that can be drawn from this study in the following way: Shortly after the emergence of animation as a genre, the establishment of Disney Studio and the animation of narratives such as fairy tales made this genre closely related to folklore. The inclusion of color and sound in animation has increased the audience and reinforced its importance in terms of cultural transfer. Also, the fact that countries such as Japan, in particular, include their myths in animation, has also helped popularize local cultures outside the Western world. Turkish animation art, on the other hand, has reached a popular point, especially with the establishment of TRT Children's Channel, although it emerged in the 1950s. The inclusion of animations containing elements of Turkish culture in the mentioned channel is also important for the popularization of Turkish culture. In short, animation has a great importance in the popularization of culture today. 


\section{Giriş}

Kültür, zamana ve mekâna göre çeşitli değişiklikler gösteren dinamik yapıda bir olgudur. Özellikle değişen zaman şartlarına bağlı olarak kültür aktarımı gibi konularda köklü değişiklikler meydana gelmiştir. Radyo, televizyon, bilgisayar, gibi teknolojik aletlerin icadından önce kültür aktarımı büyük oranda anne, baba, kardeş, nine, dede, arkadaş gibi sözlü kaynaklar vasıtasıyla gerçekleşmekteyken bu aletlerin icadından ve yaygınlık kazanmasından sonra büyük oranda dijital alanlara taşınmıştır. Kültür aktarımı konusunda yaşanan bu dönüşüm, kültür çağları kavramının ortaya çıkmasına olanak tanımıştır. Walter J. Ong, “...yazı ve matbaa kavramlarının varlığını bile bilmeyen, iletişimin yalnız konuşma dilinden oluştuğu kültürleri, "birincil sözlü kültür" olarak nitelendirirken günümüzün ileri teknolojisiyle hayata giren telefon, radyo, televizyon ve diğer elektronik araçların "sözlü" niteliklerini, üretimini ve işlevini ise "ikincil sözlü kültür"” olarak tanımlamaktadır (2013: 23-24).

Kültürün farklı alanlardaki aktarımı, halk bilimciler arasında hem "halk" hem de "alan" kavramlarının yeniden düşünülmesine de sebep olmuştur. Nitekim Alan Dundes halkı en azından ortak bir faktörü paylaşan herhangi bir insan grubu (2006: 16) olarak tanımlarken bu tanımdaki dönüşüme paralel olarak Ruhi Ersoy da folklorik malzemenin bulunduğu alan kavramının yeni boyutlar kazandığını belirtir (2012: 8).

Buradan yola çıkarak birçok kültürel ögeyi içerisinde barındıran animasyonun, bahsedilen farklı 'alan'lardan biri olarak halk bilimciler için bir inceleme konusu teşkil ettiği söylenebilir. İlk örneklerine yaklaşık bir asır önce rastlanan animasyonun bu süre içerisinde oldukça büyük gelişmeler göstererek yetişkinlere de hitap eder hâle geldiği ve 21. yüzyılın en önemli kültür aktarım kanallarından biri olduğu görülmektedir.

Bütün bu bilgileri göz önünde bulundurarak bu çalışmadaki temel amaç, kültürel ögelerin popülerleştirilmesi ve yerel kültürlerin küresel ölçekte tanınması noktasında animasyonun nasıl bir misyonu olduğunu, animasyon tarihi üzerinden incelemektir. Böylece animasyonun kültür aktarımı konusundaki etkisinin daha net bir şekilde görüleceği öngörülmektedir. Çalışmada hem Türkiye dışındaki hem de Türkiye'deki animasyon tarihi inceleme konusu yapilmaktadir.

\section{Animasyon nedir?}

Türkçeye genellikle canlandırma olarak çevrilen animasyon, "tek tek resimleri ya da devinimsiz nesneleri, gösterim sırasında devinim duygusu verebilecek biçimde düzenleme ve filme aktarma işi” (Özön, 2000: 133) olarak tanımlanabilir. Türkiye'deki genel algıya göre iki boyutlu animasyonlar "çizgi film", son zamanlarda yapılan üç boyutlu bilgisayar animasyonları ise "animasyon film" olarak nitelendirilmektedir. Özge Samancı'ya göre "çizgi film" animasyon sinemasının sınırlı bir kısmını karşılayan ve temelde çizgiye dayanan iki boyutlu animasyondur (2004: XII). Bu nedenle çalışmada, bütün bu filmler "animasyon film" olarak nitelendirilmiş, "çizgi ve animasyon film” diye bir ayrım gözetilmemiştir. 
Animasyon filmlerin iki boyuttan üç boyuta geçmesi ve bilgisayar kullanılarak hazırlanması, seslendiği hedef kitlesinde de bazı farklılıklar ortaya çıkarmıştır. İki boyutlu animasyon, genellikle çocuklara hitap ederken üç boyutlu animasyon, hem çocuklar hem de yetişkinlere hitap eder hâle gelmiştir. Bu durumun temel nedeni, üç boyutlu animasyonlarda gerçek karakter ve mekânlara yer verilerek animasyonun gerçeğe yaklaştırılmasıdır. Bahsi geçen değişimler animasyonu, kültür aktarımı konusunda daha önemli bir yere getirmektedir. Çünkü kitlesel erişime imkân veren böyle bir türün, aynı ailedeki hem yetişkinlere hem de çocuklara hitap etmesi, kültür aktarımındaki bütünlükçü yaklaşıma da uygun düşmektedir.

\section{Kültür aktarımı açısından Türkiye dışındaki animasyon tarihi}

Dünyadaki ilk animasyon filmlerin, hareket illüzyonu yaratması amacıyla bir defterin kenarına çizilen resimlerin, arka arkaya oynatılması ile ortaya çıktığı düşünülse de durum tam olarak böyle değildir. İlk animasyon filmler, flaş skeç yöntemi ile hazırlanmıştır. Flaş skeç yöntemine uygun olarak Blackton tarafından 1906 y1lında çekilen Komik Yüzlerin Gülünç Evreleri / Humorous Phase of Funny Faces adlı film, animasyonun ilk filmi olarak bilinmektedir (bk. Şekil 2). Émile Cohl tarafından 1908 yılında yapılan Fantasmogire adlı filmde, çizimler mürekkeple kâğıt üzerine çizilip oradan fotoğraflanmıştır. Aradan çizim tahtasının çıkarılması ile bilinen anlamda animasyona bir adım daha yaklaşılmıştır. Bununla birlikte ilk dönem animasyon tarihini anlamlandırmak için Winsor McCay iyi bir örnek oluşturur. Yapmış olduğu filmlerde dönem koşullarının yansımalarını bulmak mümkündür. Küçük Nemo / Little Nemo (1991), Dinozor Gertie / Gertie the Dinosaur (1914), Uçan Ev / The Flaying House (1921) bu filmlerinden bazılarıdır. 1918-1956 y1lları arasında animasyon filmler yapan Max Fleischer, gerçek nesnelerin kaydedilmiş hareketlerini animasyon kâğıdına aktarmayı başarmıştır. Böylece animasyon karakterlerinin gerçek bir aktör gibi hareket etmesi sağlanmıştır (Akt. Samancı, 2004: 4-25).

Animasyonun yukarıda bahsedilen ilk denemeleri, bir tür olarak ortaya çıkma sürecini özetlemektedir. Bu dönemde animasyon, henüz kültürel bir altyapıya sahip değildir. Fakat ilk dönem animasyonlarından olan Dinozor Gertie, Uçan Ev gibi yapımlar aslında animasyonun masal ile olan bağlantısı ve dolayısıyla folklorik yapısı hakkında ipuçları vermektedir. Sözü geçen bu ilk yapımların, içerisinde barındırdığı fantastik unsurlar nedeniyle, kısa süre içinde folklorik bir altyapıyı esas alacağına kanıt olarak gösterilebilir. Animasyonun folklorik bir altyapıyı esas alması, onu bir tür olarak kültür aktarımında oldukça önemli bir noktaya taşımaktadır. Nitekim değişen zaman şartları ile birlikte animasyon, çocukların en fazla ilgi gösterdiği tür konumuna yükselmiştir. Animasyonun kültür ile olan bağının güçlenmesindeki en önemli noktalardan biri Disney Stüdyosu'nun kurulmasıdır.

1920’li yıllardan sonra birçok film stüdyosu kurulmasına rağmen, piyasanın tek hâkimi Disney Stüdyosu'dur (Samanc1, 2004: 35). Disney Stüdyosu, gerçekçi tarzı yakalamak için iki teknik sorunu, yaptığı denemelerle çözerek ilk sesli animasyon olan İstimbot Willic / Steamboat Willic (1928) ve ilk renkli animasyon film olan Saçma Senfoni / Silly Symphony ve Ağaçlar ve Çiçekler / Flowers and Trees (1932) adlı filmleri üretmiştir (Samanc1, 2004: 39) (bk. Şekil 2). 
Bununla birlikte ilk uzun metrajlı film olan Pamuk Prenses ve Yedi Cüceler / Snow White and the Seven Dwarfs de bu döneme aittir (Tezcan Balta, 1990: 4) (bk. Şekil 3). Disney Stüdyosu ile eş zamanlı var olan diğer ünlü stüdyolardan bazıları; Terrytoons, Walter Lantz, Warner Brothers (WB), Metro-Goldwyn-Moyer (MGM), United Ptoductions America (UPA) gibi stüdyolardır.

Disney Stüdyosu; animasyonu kültür aktarımı konusunda önemli bir yere getirecek olan, ses ve renkli görüntü olayını çözmüş ve animasyonun izlenebilirliğini artırarak popüler bir tür hâline getirmiştir. Böylece animasyon yetişkinlere de hitap eder bir seviyeye ulaşmıştır. Disney Stüdyosu'nun kültür aktarımı açısından asıl önemi, yaptığı animasyonlarda kimi zaman folklorik bir alt yapıyı kullanmaları kimi zaman ise doğrudan folklorik bir anlatıyı filme çekmeleridir. Bunun en belirgin örneği, Grimm Kardeşler tarafından derlenen Pamuk Prenses ve Yedi Cüceler masalıdır. Birçok araştırmacıya göre Grimm masallarının uluslararası bir üne kavuşmasının temel nedeni, animasyon gibi çağdaş yaratımlarının üretilmesidir. Animasyon gibi çağdaş yapımlar, kültürel bir ögeyi (Pamuk Prenses ve Yedi Cüceler masalı gibi) popülerleştirmekle kalmayıp yerel kültürlerdeki benzer ögeleri de yok olma sürecine doğru sürüklemektedir. Bu açıdan bakıldığında animasyonun kültürel emperyalizm için bir aracı olduğunu söylemek mümkündür. Fakat 21. yüzyılda, kültürel emperyalizme karşıt olarak yine yerel kültürlerde yapılacak animasyon gibi çalışmalarla engel olunabileceğini ve kültürel ifade çeşitliliğinin de bu şekilde sağlanabileceğini söylemek mümkündür.

Disney Stüdyosu'nun, masal altyapısını kullanarak oluşturduğu animasyonlar yalnızca çocuklara hitap etmekle kalmamış, aynı zamanda yetişkinler üzerinde de ilgi uyandırmıştır. Thompson'un görüşleri de bu düşünceyi destekler niteliktedir: Özellikle hareketli çizgi filmler olmak üzere sinema, masal anlatanın en başarılı aracıdır. Halkın hayal gücünde yer alan yaratıklar bu şekilde kolaylıkla oluşturulmakta ve bunlara hayata dair nitelikler verilmektedir. Kuşkusuz 1946'ya dek bunların içindeki en iyi örnekler Walt Disney üretimi olan 1939 yapımı Pamuk Prenses ve Yedi Cüceler (Snow White and the Seven Dwarfs)'dir. Masallara ilgisini uzun süre önce yitiren çok sayıda yetişkin, beklemedikleri bir şekilde halkın hayal gücüne ilişkin bu eski ürünlerden büyük zevk almıştır (Akt.: Koven, 2014: 119).

Amerika Birleşik Devletleri'nin dışında kurulan birçok animasyon stüdyosu da bu sanatın gelişmesine katkı sağlamıştır. İngiltere'de üretilen ilk animasyon film, 1945 yapımı Handling Ships olarak görünse de yaygın dağıtıma çıkan ilk film, 1954 yapımı Hayvan Çiftliği / Animal Farm adlı filmdir. Filmin senaryosu George Orwell'ın aynı isimli kitabından uyarlanmıştır. İlk Fransız animasyon filmi 1930 yapımı Le Roman de Renard adlı filmdir (Kalkan, 2014: 13). Animasyonun önde gelen ülkelerinden biri de Belçika'dır. Öykü yazarı Peyo adıyla tanınan Pierre Culliford, 1957 yılında Smurf / Şirinler adlı filmi yapmıştır (Hünerli, 2005: 41). Bununla birlikte İtalya, Hollanda, Almanya, Rusya, Çekoslovakya, Romanya, Bulgaristan, Polonya, Macaristan, Çin gibi ülkelerde de animasyon filmler üretilmiştir.

Görüldüğü üzere Avrupa'da da muhtelif zamanlarda birçok animasyon film üretilmiştir. Bunlardan Belçika yapımı olan Şirinler, günümüzde kültür ekonomisi alanında çok fazla kullanılan bir animasyondur. Zira Türkiye'de de büyük bir izleyici kitlesine sahip olan Şirinler, bunun doğal bir sonucu olarak oyuncak, süs eşyası, kırtasiye, giyim sektörü vb. birçok alanda değerlendirilmektedir. Şirinler animasyonunun, gerçek kişiler ile birlikte, birisi 
2011 diğeri ise 2013 yılında olmak üzere, iki tane animasyon filmi daha çekilmiştir ve burada yer alan karakterler, sürpriz yumurta içinde, oyuncak olarak tüketiciye sunulmuştur. $\mathrm{Bu}$ durum ilk bakışta çok basit bir olgu gibi görünse de aslında büyük bir pazar oluşturmaktadır. Özelikle, Şirinler koleksiyonunu tamamlamak için birçok yetişkinin de sürpriz yumurta aldığı katılımcı sözlükler aracılığıyla tespit edilmiştir. Örneğin "Sapan” adlı kullanıcı, bu konu hakkında şöyle bir açıklama yapmıştır: ${ }^{2}$

"Şahsımı ziyadesiyle ruh hastasına çevirmiş koleksiyon. Onlarca aldım bir tane bile çıkmadı. Etrafımdakiler seriyi tamamladı. Benim bir Şirin’im bile yok derken bugün Bebek Şirin çıktı. Ofiste öyle bir çığlık atmışım ki arkadaş yan odadan panikle firlayıp geldi. Bana bir şey oldu sanmış. Yaygaranın nedenini anlayınca da "Senin zekâ yaşın kaç?" deyip gitti. Hemen seride Bebek Şirini eksik olan arkadaşla takasa girdim. 5 Şirin karşılığı takasta anlaştık. Yaptım bunu, evet." (URL-1). "Eindaclub” adlı kullanıcının yorumu ise şöyledir:

"Eski çalıştığım ofisteki kızların her öğlen Kinder sürpriz alıp tamamlamaya çalıştığı koleksiyon. Koleksiyon tamamlandığında serinin gözbebeği olan Şirine'nin kimin olacağı konusunda kısa bir belirsizlik yaşanmış, ancak kıdem olarak üstün olan hanım kızımız Şirine'yi kapmıştır" (URL-2).

Görüldüğü gibi animasyon vasıtasıyla kültür ekonomisine dönüştürülen bir oyuncak, hem çocuklara hem de yetişkinlere hitap edebilmektedir. Bu durum, milyonlarca oyuncağın satılmasının yanı sıra bu oyuncak etrafında oluşan kültürün de aktarılmasını sağlamaktadır. Buradan temel olarak şu çıkarımı yapmak mümkündür ki kültür ekonomisi, ekonomik bir sistem olmanın yanı sıra kültür aktarımının gerçekleşmesine de büyük katkıları olan bir olgudur. Demek ki animasyon, yalnızca boş vakitlerin eğlenceli geçmesini sağlayan kurgu değil, aynı zamanda büyük bir pazar gücünü elinde bulunduran çağdaş bir türdür.

Japonya'da 1930'lu yıllardan beri küçük çapta yapılan animasyonu, Osamu Tezuka milyon dolarlık bir endüstriye dönüştürmüştür. Tezuka'nın 1963 yılında yaptığı Tetsuan Atoma / Astro Çocuk adlı animasyon, Japonya'nın bu alanda söz sahibi olmasını sağlamıştır (Whitehead, 2012: 113). Japon animeleri, çocuklardan çok yetişkinlere hitap etmiştir. Bu animelerde gözler, kollar ve bacaklar normalden daha büyük çizilmiştir. Disney filmlerinin aksine, animelerde hayvanlar çok fazla yer almaz. Anime karakterleri, çoğu zaman gerçek insanlardan oluşur. Üstün güçleri olan bu savaşçılar özgürlük için mücadele ederler. Bunun haricinde robotlar, mitolojik yaratıklar, canavarlar, ruhlar başlıca anime karakterleridir (Kalkan, 2014: 14). Japon animesi konusunda Hayao Miyazaki adından bahsedilmesi gerekmektedir. Yaptığı filmlerle Japon animesini üst düzeye taşıyan Miyazaki, 2001 yapımı Sen To Chihiro No Kamikakushi adlı filmi ile Oscar kazanmıştır (Whitehead, 2012: 115).

Japonya tarafından üretilen animeler, kültür aktarımı açısından büyük önem taşımaktadır. Çünkü Japonya, Batı'dan aldığı animasyon tekniklerine kendi kültürünü, özellikle mitlerini ekleyerek yeni bir tür oluşturmuştur. Zaten animelerin içeriği incelendiğinde karakterlerin, mitolojik kahramanlarla büyük benzerlik taşıdığı görülecektir. Japonya'nın, animelere kendi mitolojik ögelerini dâhil etmesi, kültürlerinin popülerleşmesini sağlayan temel olgulardan biridir. Bugün Amerikalı veya Avrupalı bir yapımcının Japon kültürü ile ilgili bir animasyon 
hazırlaması, yukarıda bahsedilen durumdan kaynaklanmaktadır. Bu örnek gösteriyor ki animasyon, kültürün popülerleşmesinde önemli bir yere sahiptir. Ayrıca bu durum, mitolojiyi kullanarak popüler bir tür yaratmak için mutlaka Batı kültür dairesinde yer almak gerektiği düşüncesini de geçersiz kılmaktadır.

1980'li yıllarda gerçekleşen teknolojik gelişmeler, ilk bilgisayar animasyonu denemelerini başlatmıştır. Bilgisayar animasyonunu, anlatının önemli bir parçası olarak gören ve bunu kullanan filmlerin çoğu hem maliyetli hem de başarısız olmuştur. Disney'in Steve Lisberger 'in Tron (1982) ve Lorimar'ın Son Yıldız Savaşçısı (1984) bunlardan birkaçıdır (Whitehead, 2012: 121-122). 1984 y1linda John Lasseter, The Adventures of Andre and Wally B. / Andre ve Wally B. 'nin Maceraları isimli ilk kısa bilgisayar animasyon filmini tamamladı. Pixar şirketi tarafından 1995 yılında çekilen Oyuncak Hikâyesi / Toy Story adlı film, tamamı bilgisayar animasyonu olan ilk filmdir. Pixar şirketi 2001 yılında en iyi animasyon film dalında Shrek adlı filmle Oscar ödülünü kazanmıştır. Oyuncak Hikâyesi / Toy Story (1995, 1999, 2000) (bk. Şekil 4), Karınca Z / Ant Z (1998), Shrek (2001, 2004, 2007, 2010), Buz Devri / Ice Age (2002, 2006, 2009, 2012) gibi filmler bilgisayar animasyonlarından bazılarıdır (Kalkan, 2014: 11-12).

Günümüzde animasyonlar, tamamı bilgisayar kullanılarak yapılmakta ve kullanılan bu teknoloji, animasyonu sinema görüntüleri kadar gerçekçi hâle getirebilmektedir. Ortaya çıktığı zamandan beri yetişkinlere de hitap eden bir tür olan animasyon, bilgisayar teknolojisini kullanarak bu durumu daha da belirgin hâle getirmiştir. Bugün, üretilen animasyon filmler milyonlarca kişi tarafından izlenerek hem büyük bir ekonomik sektör oluşturmakta hem de makalenin başından beri vurgulandığg gibi kültür aktarımı açısından önemli bir kanal olma yolunda hizla ilerlemektedir.

\section{Kültür aktarımı açısından Türkiye'de animasyon tarihi}

Türkiye'de animasyonun tarihi, Türk gölge oyunu Karagöz'e kadar dayandırılsa da bilinen anlamdaki animasyon, 1950'lerden sonra gelişmeye başlamıştır. Önceleri sinema reklamları için hazırlanan çizgi filmler şeklinde görülen Türk animasyon sanatı, daha sonra alanını ve tekniklerini geliştirerek varlığını ispatlamıştır (Tezcan Balta, 1900: 5). Türkiye'de animasyonun ilk denemeleri 1948-49 yılları arasında Vedat Ar'ın yöneticiliğini yaptığı bir kursla başlar. Vedat Ar'ın 1947 yılında on beş öğrencisi ile birlikte yaptığı, üç dakikalık Zeybek Oyunu adlı çalışması Türkiye'nin ilk animasyon filmidir (Onaran, 1994: 196).

1950'li yıllarda Yüksel Ünsal'ın yönetiminde Evvel Zaman Iç̧inde ve Nasreddin Hoca filmleri yapılır. Ancak filmler, laboratuvar işlemleri için gönderildiği ABD’de kaybolur (Balcığlu, 1983: 14). Daha sonra Vedat Ar, "Filmar" adlı bir stüdyo kurmuş ve burada bir yandan 2-3 dakikalık animasyon filmler üretirken bir yandan da değişik biçim araştırmaları yapmıştır (Şenler, 2005: 110).

Filmar ile aynı dönemde kurulan bir başka firma da "İstanbul Reklam Ajansı"dır. Bu ajans, başlangıçta karikatür sanatçılarına çizgi filmler hazırlatmış, görülen ilgi üzerine kadrosunu genişletip üretimini artırmıştır. Ancak bu dönemde üretilen çizgi filmler kalite açısından zayıf kalmışlardır (Aygenç, 1990: 19). 
Aynı yıllarda "Radar Reklam”ın açtı̆̆ı bir animasyon bölümü ile "Kare Reklam" adındaki bir stüdyo çalışmalara başlamış; fakat uzun ömürlü olmamıştır. Bununla birlikte "Stüdyo Çizgi” Evliya Çelebi, "Canlı Karikatür” adlı stüdyo ise Koca Yusuf ve Direkler Arası adlı filmleri yapmıştır (Atan, 1995: 27).

Animasyonun Türkiye' deki ilk denemelerinin, dünya animasyon çalışmalarından yaklaşık 50 yıl geride olduğunu söylemek mümkündür. İlk dönemdeki teknolojik gelişmelerin, geniş bir zamana yayıldığı göz önüne alındığında bu sürenin çok büyük bir fark oluşturmadığı görülmektedir. Türkiye'deki ilk dönem animasyon çalışmaları, içerisinde Nasrettin Hoca gibi birçok kültürel ögeyi barındırmasına karşın yeterince ilgi uyandırmamıştır. Türk animasyon tarihinde yaşanan bu ilk başarısızlıklar, akıllara teknolojik açıdan yetersizliği getirse de durum aslında tam olarak öyle değildir. Bahsedilen dönemde animasyon çalışmalarının başarısı yüksek teknolojiden ziyade, bu alana ilgi gösteren karikatüristlerin varlığına bağlıydı. O dönemde 10 saniyelik bir animasyon için 1000 civarı karikatür çizilmekteydi. Türkiye'de, o dönemde hiçbir karikatürist bahsedilen düzeyde çizim yapmamıştır. Bu durum ilk dönem Türk animasyonlarının başarısızlığının başat nedenini oluşturmaktadır.

1970’li yıllara gelindiğinde, Tonguç Yaşar ilk kişisel filmi Amentü Gemisi Nasıl Yürüdü? (bk. Şekil 5) ile 1970 yılında 2. Altın Koza film şenliğinde ödül almıştır. Tonguç Yaşar bu eserinde Osmanlı kaligrafi sanatı ile oluşturulan simgelere âdeta can vererek bilindik çizgi film anlayışının dışında deneysel bir araştırma ortaya koymuştur (Türker, 2011: 235). Ayrıca bu film, 900 filmin katıldığ 19 . Annecy Çizgi Film şenliğinde ön elemeyi geçerek gösterilmeye değer bulunan ilk Türk çizgi filmi olmuştur (Abalı, 2012: 106).

Karikatürist Tan Oral'ın, 1969'da yaptığı Sansür adlı animasyon film; TRT Kültür Sanat Bilim Ödülleri Kısa Film Yarışması'nda birincilik ödülü, Akşehir Nasrettin Hoca Canlandırma Film Yarışması'nda (1975) büyük ödülü kazanmıştır (Akt. Hünerli, 2005: 64). Tonguç Yaşar ile Tan Oral'ın bu tür deneysel filmleri, Türkiye'de animasyon sanatının estetik açıdan gelişmesine katkı sağlarken animasyon filmin sadece reklam filmi olmadığını da ortaya koymuştur (Abal1, 2012: 108).

1970'li y1llardan önce Türkiye'de çekilen animasyonlar, genellikle reklam amaciyla hazırlanmıştır. Bu durum animasyonun bir tür olarak gelişimini engellediği gibi, folklorik bir altyapıya sahip olarak izleyici ile buluşmasını da geciktirmiştir. 1970'li yıllar, Türk animasyonlarının gelişme göstererek ödül aldığı yıllar olmanın yanı sıra çeşitli folklorik ögelerin kullanılmaya başlandığı yıllar olarak da değerlendirilebilir.

1980’li yıllar Türk animasyonlarının yurtdışında ödüller aldığı dönemdir. 1980’li yılların ikinci yarısında Çizgi Reklam, Tunç İzberk Stüdyosu, Tele Çizgi, Animatek, Ajans Bulu, Arnet gibi birçok stüdyo, devlet kurumları için eğitici ve öğretici filmler yapmaya başlamıştır (Hünerli, 2005: 66). 1988 yılında Dede Korkut Hikâyeleri'nden alınarak çizgi filme aktarılan 50 dakikalık Boğaç Han isimli animasyon, Türkiye'nin uzun metrajlı ilk filmidir. Bu film Pasin-Benice Stüdyosu'nda Derviş Pasin tarafından yapılmıştır (Abalı, 2012: 106). Bu dönemde Dede Korkut gibi destani hikâyelerden yararlanılması, Türkiye'de animasyonun kültür aktarımına yapmış olduğu katkının önemli bir adımı olarak değerlendirilebilir. Ayrıca 
ilk dönem animasyonlarında sıklıkla kültürel ögelerden yararlanılması, animasyon ve kültür arasındaki bütünlükçü yapıya da bir atıf olarak okunabilir.

Türkiye'de ilk animasyon bölümü, 1990 y1lında Anadolu Üniversitesi, Güzel Sanatlar Fakültesi'nde Çizgi Film (Animasyon) Bölümü adı altında kurulmuştur. Anadolu Üniversitesi'nden sonra 2005 yılında Maltepe Üniversitesi'nde ve 2006 y1lında Kütahya Üniversitesi’nde Çizgi Film-Animasyon Bölümü açılmıştır. Böylece animasyona ilgili kişilerin erken yaşlarda eğitim almaları sağlanmıştır (Abalı, 2012: 109-110). Bir başka animasyon bölümü ise 2021 yılında Mimar Sinan Güzel Sanatlar Üniversitesi’nde açılmıştır. $\mathrm{Bu}$ durum da göstermektedir ki, Türkiye'de animasyona olan ilgi gittikçe artmakta ve profesyonel animatör yetiştirme konusunda devlet destekli adımlar da atılmaktadır.

01. 11. 2008'de Türkiye'nin ilk yerli çocuk kanalı olma özelliği ile TRT Çocuk yayın hayatına başlamıştır. (URL-3). 2009 yılında Türkiye'nin ilk üç boyutlu çizgi film serisi Keloğlan, Animax Animasyon Stüdyoları tarafından yapılarak TRT Çocuk kanalında yayımlanmıştır. İki sezon boyunca gösterilen Keloğlan, 2012'de reelle animasyonun birleştirildiği yeni bölümlerle ekrana gelmiştir (Abalı, 2012: 110-111). Türk masal kahramanları içerisinde önemli bir yere sahip olan Keloğlan hakkında yapılan bu animasyon film, Bayraktar'ın ifadesiyle geleneğin güncellenmesi ve gelecek kuşaklara aktarılması bağlamında başarılı bir çalışmadır (2014: 48). Bahadır Uçan ise Keloğlanın başarılı bir yapım olsa da, basmakalıp ve Batı kökenli yaklaşımlardan kurtulamadığını düşünmektedir (2018: 1142). Keloğlan animasyon dizisi her ne kadar eksiklikler barındırsa da, uzun metrajlı olması ve geniş bir izleyici kitlesine sahip olması gibi sebeplerle kültür aktarımı açısından önemli bir işleve sahiptir. Nitekim Rüştü Asyalı'nın başrol oyuncusu olarak yer aldığı Keloğlan filmleriyle popülerleşen bu masal kahramanı, bahsi geçen çizgi filmle birlikte bu popülaritesini koruyacak ve genç kuşaklar için iyi bilinen bir karakter niteliğine bürünecektir. Bununla birlikte, 1990’lı yıllar için Türk animasyonunun büyük gelişme gösterdiği yıllar olduğu söylenebilir. Bu dönemde üniversitelerde açılan bölümler, profesyonel animatörlerin yetişmesine olanak sağlamıştır. Bununla birlikte, 2008 yılında TRT Çocuk kanalının yayın hayatına başlaması, Türk animasyon tarihi için devrim niteliğinde bir gelişmedir. Ürettikleri animasyonu problemsiz bir şekilde yayınlayabilecek bir kanalın varlığı doğal olarak birçok animasyon şirketinin kurulmasına zemin hazırlamıştır. Özellikle Türk animasyon şirketlerinin kültürden yararlanması da Türk folklorunun popülerleştirilmesi açısından önem taşımaktadır. Nitekim TRT Çocuk kanalının varlığı ve buna koşut olarak animasyon şirketlerinin kurulması, yukarıda bahsedilen “Keloğlan Masalları” animasyonunun yanı sıra “Dede Korkut Hikâyeleri” gibi Türk kültüründe önemli bir yere sahip olan anlatıların animasyona çekilmesini sağlayarak adı geçen kültürel ögelerin özellikle çocuklar arasında popülerleşmesine olanak tanımıştır. Ahmet E. Aral tarafından yapılan bir araştırma bu tezi doğrular niteliktedir. Aral'ın çocuklar ile yaptığ 1 bir görüşmede Dede Korkut'u tanıyor musunuz? sorusuna; 141 çocuktan 24'ü Dede Korkut Kitabı'nı okuduğundan, 44'ü anlatıları çevresinden dinlediğinden, 70'i ise çizgi filmini izlediğinden dolayı tanıdığını söylemiştir (2015: 128). Bu durum, animasyonun kültür üzerindeki etkisini örneklendirmenin yanı sıra kültürün, bütüncül bir yaklaşımla korunması gerektiğini de göstermesi açısından kayda değerdir. Yine son yıllarda TRT Çocuk Kanalı'nda 
yayımlanan birçok animasyon dizinin kültürle olan yakın ilişkisi dikkat çekmektedir. Bunlardan Dede Korkut Hikâyeleri çizgi filmi, Dede Korkut Kitabı esas alınarak olaylar çocukların anlayacağı şekilde sadeleştirilmiş ve orijinal bir senaryo ve yeni kahramanlarla güncellenmiş bir çizgi dizidir (Aslan, 2016: 219-220). Yine TRT Çocuk Kanalı'nda yayımlanan bir dizi olan Rafadan Tayfa içerisinde barındırdığı yoğun kültür ögeler nedeniyle âdeta çağdaş bir folklorik anlatı olarak değerlendirilmeye müsaittir. Rafadan Tayfa animasyon dizisinde aşure geleneğinden çocuk oyunlarına, türkülerden halk oyunlarına kadar birçok folklorik ögeye yer verilmekte ve bu sayede kültür aktarımı açısından önemli bir misyon yüklenmektedir. ${ }^{3}$ Yukarıda örnekleri verilen animasyon dizilerin yanı sıra bugün Türkiye'de, özellikle TRT Çocuk Kanalı'nda gösterime giren birçok animasyon dizide benzer şekilde kültürel ögeleri görmek mümkündür. ${ }^{4}$ Çünkü animasyon film ya da dizilerin masal türü ile olan yakın ilişkisi, aynı zamanda kültürel bir altyapıyla da bütünleşmesini sağlamaktadır. Bu durum ilk dönem animasyonlarında olduğu gibi günümüz animasyonlarında da devam etmektedir. Böylece animasyon kültür ilişkisinin ayrılmaz yönü de ortaya çıkmaktadır.

\section{Sonuç}

Animasyon tarihi üzerinden animasyonun kültür aktarımındaki gücünün incelendiği bu makaleden çıkarılabilecek sonuçları şu şekilde özetlemek mümkündür: Öncelikle, animasyonun bir tür olarak ortaya çıktığı 20. yüzyılın başında yapılan ilk denemeler, bu türün zamanla folklorik bir anlatıya dönüşeceğini göstermektedir. Zira Disney Stüdyosu'nun kuruluşu bu durumu pekiştirmiştir. Özellikle Disney Stüdyosu'nun masal gibi anlatı türlerini filme aktarmasıyla animasyon, çağdaş bir "folklorik anlatıya" dönüşmüştür. Animasyonun folklorik bir anlatıya dönüşmesi, onu kültür aktarımı konusunda oldukça önemli bir yere getirmiş ve disiplinler arası çalışmalar için uygun bir ortam hazırlamıştır.

Animasyona renk ve sesin dâhil edilmesi, yetişkinlere de hitap etmesini ve kültür ekonomisi gibi birçok alanda kullanılmasını sağlamıştır. $\mathrm{Bu}$ durum, akıllara kültürel emperyalizm düşüncesini getirse de 21. yüzyılda kültürel ifade çeşitliliğinin sağlanması, yine yerel kültürleri esas alan animasyon çalışmaları ile olacaktır. Bunun en iyi örneği ise Japon animasyon çalışmalarıdır. Japonya Batı'dan aldığı animasyon tekniklerine kendi mitlerini ekleyerek "anime” adında bir animasyon türü oluşturmuş ve kültürünün animasyon vasıtasıyla yaşatılmasını sağlamıştır.

Türk animasyon çalışmalarının 1950'li yıllarda başladığını söylemek mümkündür. İlk dönem animasyon çalışmalarının reklam amaçlı yapılması, animasyonun bir tür olarak gelişimini engellemiştir. Bununla birlikte animasyon sanatının Türkiye'de yeterince gelişmemesi, karikatüristlerin bu alan olan ilgisizliğinden kaynaklanmaktadır. Üniversitelerde kurulan animasyon bölümleri ile özel sektördeki animasyon stüdyoları, Türk animasyon sanatının gelişimine büyük katkı sağlamıştır. Özellikle TRT Çocuk kanalının yayın hayatına başlaması ile Türk animasyon şirketleri, yaptıkları animasyonları kolayca izleyiciyle buluşturmuş ve bunun bir sonucu olarak Türk kültürüne ait anlatı, gelenek, çocuk oyunu vb. unsurların animasyonlarda temsili sağlanmıştır. 
Görüldüğü üzere animasyon, içerisinde barındırdığı folklorik altyapı sayesinde çağdaş bir anlatı olarak işlev görmekte ve kültürün kuşaklararası aktarımında büyük önem arz etmektedir. Dünyadaki ilk uzun metrajlı animasyonun Pamuk Prenses ve Yedi Cüceler, Türkiye'deki ilk uzun metrajlı animasyonun ise Boğaç Han olması, animasyon ile folklor arasındaki yakın ilişkiyi örneklendirmektedir. Günümüzde üretilen animasyonlarda da yoğun bir şekilde kültürel ögelere yer verilmesi, animasyonun kültür aktarımı ve kültürün popülerleştirilmesi konusundaki gücünü göstermesi açısından dikkat çekici bir durumdur.

\section{Notlar}

1 Flaş skeç (İng. flash sketch ): 19. yüzyılın sonlarından 20. yüzyılın başına kadar yaygın olan salon eğlencesi. Performansı yapan kişi karatahtaya çizimler yapar, tahtaya art arda eklediği çizgilerle, başlangıçta yaptığı çizimleri beklenmedik bambaşka şeylere dönüştürür; bu dönüşümlerle izleyiciyi şaşırtır ve bir hikâye anlatır (Samanc1: 2004: 133).

2 Kullanıcılar tarafından yapılan yorumlardaki yazım ve noktalama yanlışları, makalenin yazarı tarafından düzeltilerek verilmiştir.

3 Rafadan Tayfa animasyon dizisi ve kültür aktarımı konusundan ayrıntılı bilgi için bk. (Aslan, 2018), (Aslan ve Yilar, 2019)

4 TRT Çocuk Kanalı'nda Keloğlan, Dede Korkut Hikâyeleri ve Rafadan Tayfa animasyon dizilerinin yanı sıra kültürel ögelerin sıklıkla kullanıldığı birçok animasyon diziye de yer verilmektedir. Bu animasyon dizilerle ilgili yapılan birkaç örnek çalışma için bk. (Karakuş, 2016), (Türkmen, 2012), (Fedakar, 2011).

\section{Kaynakça}

Abalı, N. (2012). Türkiye'de animasyonun dünü ve bugünü. Ayllk Bilişim Kültür Dergisi, $147,106-113$.

Aral, A. E. (2015). Uygulamalı halk bilimi açısından eğitim sürecinde Dede Korkut. Ege Üniversitesi Türk Dünyası Incelemeleri Dergisi, 15/2, 123-138.

Aslan, E. (2015). Keloğlan animasyon filmi örneğinde kültürel animasyon ve kültür ekonomisi. Ankara, Gazi Üniversitesi Sosyal Bilimler Enstitüsü. Yayımlanmamış yüksek lisans tezi.

Aslan, E. (2016). Dede Korkut hikâyeleri animasyon filminin kültür aktarımı açısından incelenmesi. III. Uluslararas1 Türk Dünyası Kültür Kongresi: Dede Korkut ve Türk Dünyası. İzmir, 1, 217-224.

Aslan, E. (2018). Dijital kültürde kültür aktarımı: Rafadan Tayfa animasyon dizisinde "aşure günü" örneği. 9. Milletlerarası Türk Halk Kültürü Kongresi. Ordu, 3, 329-334.

Aslan, O. ve Yılar, Ö. (2019). Halk bilimi unsurlarının gelecek kuşaklara aktarımında çizgi filmlerin rolü: Rafadan Tayfa örneği. Nevşehir Hacı Bektaşi Veli Üniversitesi Sosyal Bilimler Dergisi, 9(2), 646-669.

Atan, U. (1995). Animasyonun kültür aktarımındaki yeri. Konya, Selçuk Üniversitesi Sosyal Bilimler Enstitüsü. Yayımlanmamış yüksek lisans Tezi.

Aygenç, F. (1990). Kukla animasyon üzerine bir deneme çalışması. Hacettepe Üniversitesi Sosyal Bilimler Enstitüsü. Yayımlanmamış yüksek lisans sanat eseri. 
Balcığlu, S. (1983). Cumhuriyet dönemi Türk karikatürü. Türkiye İş Bankası Kültür.

Bayraktar, Z. (2014). Geleneğin güncellenmesi bağlamında masaldan çizgi filme keloğlan tipi üzerine. Türk Dili ve Edebiyatı Dergisi, 49, 19-51.

Dundes, A. (2006). Halk kimdir? (M. Ekici, Çev). Halk biliminde kuramlar ve yaklaşımlar 1. (M. Öcal Oğuz vd. Ed). Geleneksel. 11-26.

Ersoy, R. (2012). Halk bilimi çalışmalarının gelişimine paralel olarak "alan araştırması”" kavramını yeniden düşünmek. Millî Folklor, 94, 5-13.

Fedakar, P. (2011). Çizgiyi aşanlar: Cille Türk mitolojisinin çizgi filmde kullanılması ve çizgi filme aktarılması. Türk Dünyası İncelemeleri Dergisi. 11(1), 107-119.

Hünerli, S. (2005). Canlandırma sineması üzerine. Es.

Kalkan, F. (2014). Animasyon sineması ve hayvan karakterleri. Başka Yerler.

Karakuş, N. (2016). Maysa ve Bulut isimli animasyon çizgi filmin kültürel ögeler açısından incelenmesi. Mustafa Kemal Üniversitesi Sosyal Bilimler Enstitüsü Dergisi, 13(34), 134-149.

Koven, J. M. (2014). Halk bilimi çalışmaları, popüler film ve televizyon: Gerekli bir eleştirel araştırma. (G. Yüksel Halıcı, Çev). Uygulamalı halk bilimi. (M. Ö. Oğuz vd. Ed) Geleneksel. 118-138.

Onaran, Â. Ş. (1994). Türk sineması (1. Cilt). Kitle.

Ong, J. W. (2013). Sözlü ve yazılı kültür sözün teknolojileşmesi. (S. Postacığlu Banon. Çev). Metis.

Özön, N. (2000). Sinema, televizyon, video, bilgisayarlı sinema sözlüğü. Kabalc1.

Samanc1, Ö. (2004). Animasyonun önlenemez yükselişi. İstanbul Bilgi Üniversitesi.

Şenler, F. (2005). Animasyon tarihi, teknikleri ve Türkiye'deki yansımaları. Hacettepe Üniversitesi Türkiyat Araştırmaları Dergisi, 3, 109-114.

Tezcan Balta, G. (1990). Animasyon üretim tekniklerinin deneysel analizi üzerine bir araştırma. Hacettepe Üniversitesi Sosyal Bilimler Enstitüsü. Yayımlanmamış yüksek lisans sanatta yeterlilik eseri.

Türker, H. İ. (2011). Canlandırmanın tarihçesi ve Türk canlandırma sanatı. İnönü Üniversitesi Sanat ve Tasarım Dergisi, 1(2), 227-241.

Türkmen, N. (2012). Çizgi filmlerin kültür aktarımındaki rolü ve Pepee. Cumhuriyet Üniversitesi Sosyal Bilimler Dergisi. 36(2), 139-158.

Uçan, B. (2018). Türk çizgi filmlerinde kültürel kodlamalar. Uluslararası Sosyal Araştırmalar Dergisi. 11(55), 1134-1144.

Whitehead, M. (2012). Animasyon filmler (A. Turuskan, Çev) Kalkedon.

\section{Elektronik kaynaklar}

URL-1: Ekşi Sözlük kullanıcı yorumu. (Erişim Tarihi: 22. 06. 2016). (https://eksisozluk.com/kindersurprise-sirinler-koleksiyonu--3271441).

URL-2: Ekşi Sözlük kullanıcı yorumu. (Erişim Tarihi: 22. 06. 2016). (https://eksisozluk.com/kindersurprise-sirinler-koleksiyonu--3271441? $\mathrm{p}=2$ ).

URL-3: (Erişim Tarihi: 26. 01. 2017). (http://www.trt.net.tr/Kurumsal/s.aspx?id=tarihce).

URL-4: Komik Yüzlerin Gülünç Evreleri adlı filmden bir görüntü. (Erişim Tarihi: 10. 02. 2017). (http:// archives.frederatorblogs.com/talk_to_the_snail/2006/04/06/happy-\%09100th animation/). 
URL-5: Saçma Senfoni ve Çiçekler ve Ağaçlar adlı filmden bir görüntü. (Erişim Tarihi: 10. 02. 2017). (http://ashley-olsenblog.blogspot.com.tr/2008/03/lost-art-of-disney-250-original-cels.html).

URL-6: Pamuk Prenses ve Yedi Cüceler adlı filmden bir görüntü. (Erişim Tarihi: 10. 02. 2017). (http:// www.waltdisney.org/exhibitions/snow-white-and-seven-dwarfs-creation-classic).

URL- 7: Oyuncak Hikâyesi adlı filmden bir görüntü. (Erişim Tarihi: 10. 02. 2017). (http://pixartimes. com/2011/11/11/first-look-toy-story-small-fry/).

URL-8: Amentü Gemisi Nasıl Yürüdü? adlı filmden bir görüntü. (Erişim Tarihi: 10. 02. 2017). (https:// mutlaktoz.wordpress.com/2014/02/10/amentu-gemisi-nasil-yurdu/)

\section{Şekiller}

Şekil 1. (URL-4).

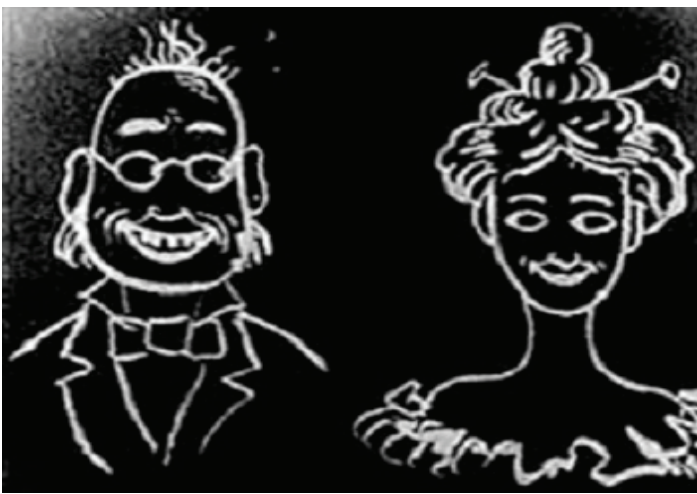

Şekil 2 . (URL-5).

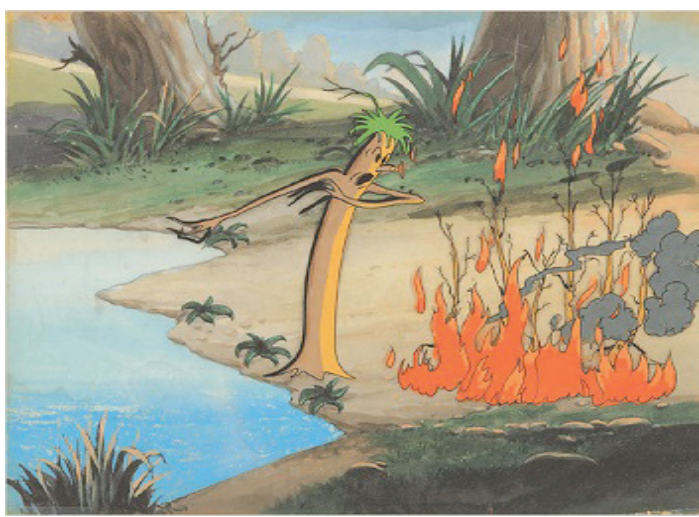

Flaş skeç geleneğine uygun olarak Blackton tarafinda 1906 yılında çekilen Komik Yüzlerin Gülünç Evreleri / Humorous Phase of Funny Faces adlı filmden bir görüntü.

İlk renkli animasyon film Saçma Senfoni ve Çiçekler ve Ağaçlar / Silly Symphony Flowers and Trees (1932) adlı filmden bir görüntü. 
Şekil 3. (URL-6).

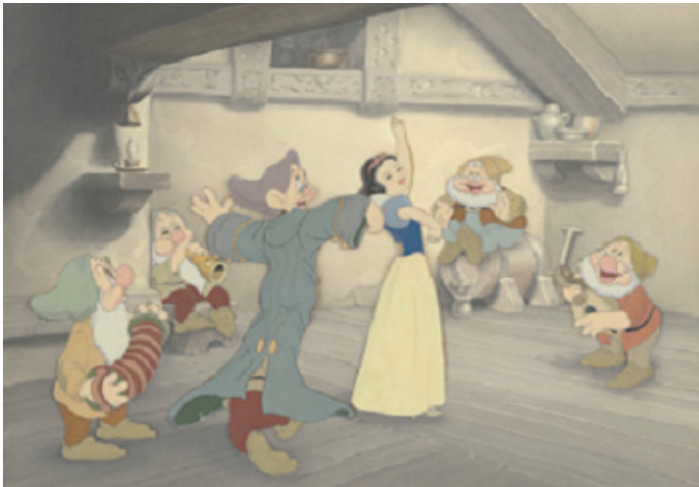

İlk uzun metrajlı film olan Pamuk Prenses ve Yedi Cüceler / Snow White and the Seven Dwarfs adli filmden bir görüntü.

Şekil 4. (URL-7).

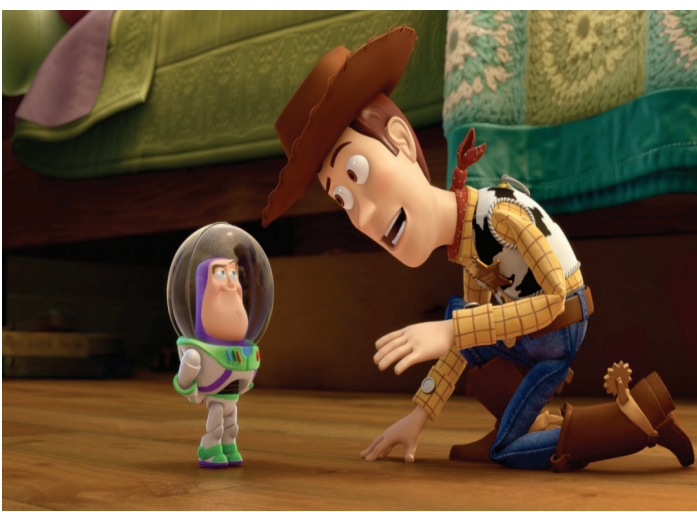

Pixar şirketi tarafından 1995 yılında çekilen ve tamamı bilgisayar animasyonu olan Oyuncak Hikâyesi / Toy Story adlı filmden bir görüntü.

Şekil 5. (URL- 8).

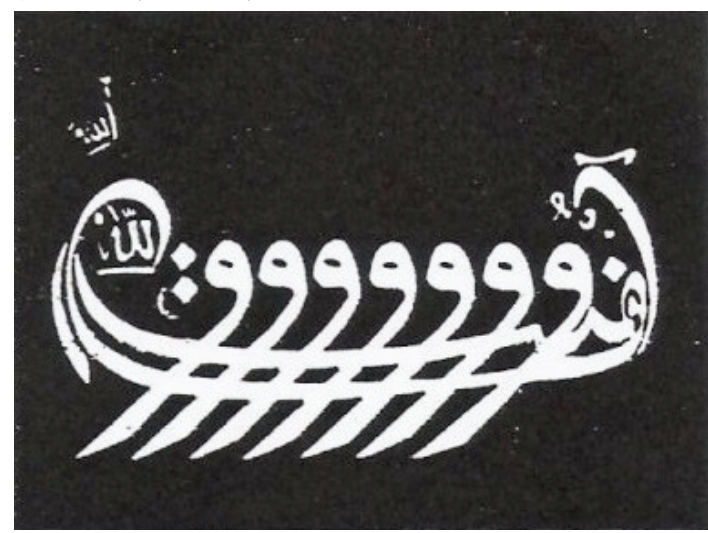

Amentü Gemisi Nasıl Yürüdü? adlı Tonguç Yaşar imzalı filmden bir görüntü.

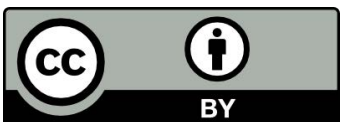

$\mathrm{Bu}$ eser Creative Commons Atıf 4.0 Uluslararası Lisansı ile lisanslanmıştır. (This work is licensed under a Creative Commons Attribution 4.0 International License). 